\title{
Recognition and Application of Reading Strategies : Case of Tunisian University Learners
}

Maha Dallagi (Corresponding author)

Higher Institute of Applied Studies in Humanities of Zaghouan, University of Tunis, Tunisia

Email: maha_dallagi@yahoo.co.uk

Received: 28/11/2020

Accepted: 25/01/2021

Published: 01/03/2021

Volume: 2 Issue: 2

How to cite this paper: Dallagi, M. (2021). Recognition and Application of Reading Strategies : Case of Tunisian University Learners. Journal of Practical Studies in Education, 2(2), 14-24

DOI: https://doi.org/10.46809/jpse.v2i2.19

Copyright $(\odot 2020$ by author(s) and Global Talent Academy Ltd. This work is licensed under the Creative Commons Attribution International License (CC BY 4.0).

http://creativecommons.org/licenses/by/4.0/

\section{(c) $($ )}

\begin{abstract}
Reading is perhaps the most important skill for second language learners in academic contexts (Grabe, 2014; Lynch \& Hudson, 1991). The need to be able to read in English is especially felt at the tertiary level where most of the academic sources are in English. Yet, Reading is one of the skills that learners often find extremely difficult (Littlewood \& Liu, 1996). One major reason for these difficulties is the use of reading strategies and importance of lower-level processes in reading. This study investigated to the choice and frequency of reading strategies by Tunisian tertiary level students $(\mathrm{N}=147)$. It aimed to point out whether variables such as Specialty, Proficiency and Gender correlated with the broad categories of Reading strategies identified by Mokhtari and Sheorey (2002). Results unveiled little difference between Hard Science and Soft Science majors in their use of Reading strategies. Statistical analyses demonstrated no relationship between proficiency level, gender, and strategy use.
\end{abstract}

Keywords: Reading Strategies, Efficiency, Specialism, Proficiency, Gender

\section{Introduction}

Research in learning strategies was initiated in the early 1930s, and much research has highlighted, since then, the impact learning strategies could have on learning acquisition while it interacts with different variables. Different studies identified a significant impact of diverse factors (motivation, age, gender, origin...) on learning strategy choice (Oxford \& Nyikos, 1989; Lee \& Oxford, 2008; Mochizuki, 1999; Peacock \& Ho, 2003). In the Tunisian context, various variables and factors seem to impact students' strategies in acquiring English, which is an additional language, learnt after French. Specialism, Proficiency, and Gender are variables that might significantly impact the choice of strategies. This paper investigates whether Hard science majors are more skilled learners than Soft Science majors, and if there is one difference at the proficiency level. It seeks to contribute to an understanding of the relationship between academic field and strategy use in Reading. The findings of the results aim to underline the importance of understanding Reading strategies and the efficient application of the latter when dealing with academic texts. 
The present study focuses on Reading strategies by using Mokhtari and Sheorey's taxonomy (2002). It examines and compares how students majoring in different disciplines make use of strategies while reading EAP texts, and whether there is relationship between strategy use and proficiency level.

\section{Literature Review}

\subsection{Reading strategies: Definition and Taxonomy}

English has become the "link" language and a relatively good command of reading skills in ESL is essential for students as a means of access to information. Levine, Ferenz and Reeves (2000, p. 1) maintain that "the ability to read academic texts is considered one of the most important skills that the university students of English as a second language (ESL) and as a foreign language (EFL) need to acquire." Yet, this requires an adequate use of Reading processes and strategies. Readers resort spontaneously to some basic reading strategies when they attempt to comprehend a text (Pritchard, 1990).

Janzen (2002) states that the reader makes use of a number of strategies ranging from simple "fix-up strategies", such as simply rereading difficult segments and guessing the meaning of an unknown word from context, to more comprehensive strategies, such as summarizing and relating what is being read to the reader's background knowledge, and here reading converges with writing. Block (1986, pp. 463-464) states: "Knowledge about the process, not just the product of reading is needed if we are to move from head-scratching to designing programs which truly meet the needs of our students."

Brown (2007, p. 119) defines reading strategies as "specific methods of approaching a problem or task, modes of operation for achieving a particular end, planned designs for controlling and manipulating certain information. Reading strategies indicate how readers conceive a task, what textual cues they attend to, how they make sense of what they read, and what they do when they do not understand (Block,1986). Mokhtari (2000) classified reading strategies into three categories: metacognitive strategies, cognitive strategies, and support strategies.

Metacognitive Reading strategies are those intentional, carefully planned techniques by which learners monitor or manage their reading. Auerbach and Paxton (1997, pp. 240-241) indicate that "metacognitionis knowledge of strategies for processing texts, the ability to adjust strategies as needed". Metacognition is the combination of conscious awareness of the strategic reading processes and the actual use of reading strategies (Sheorey \& Mokhtari, 2001). These strategies include having apurpose in mind, previewing the text as to its length and organization, using typographical aids, tables and figures. O'Malley and Chamot (1990) regard metacognitive strategies as significant techniques to successful second language learning. Carrell (1998) holds the view that successful reading strategy use varies according to its metacognitive employment. Pressley and Afflerbach (1995) and Sheorey and Mokhtari (2001) observe that strategic awareness and monitoring of the comprehension process are critically important aspects of skilled reading.

Tercanlioglù (2004) identifies techniques such as adjusting one's speed of reading when the material becomes more difficult or easier, guessing the meaning of unknown words, and re-reading the text for improved comprehension as being cognitive strategies.

Mokhtari and Sheorey (2002) established a different taxonomy and classified reading strategies into three broad categories: Global Reading Strategies (GLOB), Problem- Solving Strategies (PROB), and Support Reading Strategies (SUP). This taxonomy was used to classify the reading strategies in the Survey of Reading Strategies (SORS).

(i)Global Reading Strategies (GLOB) are generalized techniques that set the stage for the reading act. In an earlier version of SORS, GLOB strategies were identified as Metacognitive strategies.

(ii) Problem-solving Strategies (PROB) are the counterparts of cognitive strategies in SORS ( $1^{\text {st }}$ version). They are repair strategies that are used when problems develop in understanding textual information.

(iii) Support reading Strategies (SUP) consist of using support mechanisms or tools aiming at facilitating reading comprehension process (for instance, use of reference materials like dictionaries and other support systems). Tercanliòglu (2004) defines support strategies as techniquesmeant to aid the reader in comprehending the text.

It is interesting to notice that scholars identified almost the same recurrent strategies but classified them differently. While Flavell (1979) characterizes note-taking as a cognitive strategy, Tercanliòglu (2004) identifies it as a support strategy. Though these techniques are diverse, Mokhtari and Sheorey (2002) maintain that the three sets of strategies complete and interact with each other in constructing meaning. However, it is worth mentioning that reading processes and strategies might not only be motivated by different purposes but might also be impacted by different variables.

\subsection{Reading Strategies and Variables}

The relationship between variables and learning strategies has been significantly highlighted in research (Oxford, 1989; Oxford and Nyikos, 1989; Peacock, 2001; Peacock \&Ho, 2003).

Oxford (1989) has listed different variables that have had a significant impact on learning strategies. These include 1) the language being learned, 2) language proficiency, 3) degree of metacognitive awareness, 4) gender, 5) affective variables, such as attitudes, motivation and language learning goals, 6) specific personality traits, 7) overall personality type, 8) learning style, 9) career orientation or field of specialization, 10) national origin, 11) aptitude, 12) language teaching methods, 13) task requirements, and 14) type of strategy training.

In a large study, Oxford and Nyikos (1989) investigated variables that affect learning strategies used by 1200 students. They concluded that motivation, field of specialization, self-perceived proficiency and gender are major determining factors of learning strategies. Peacock (2001) and Peacock and Ho (2003) highlighted the impact of specialism on Strategy use. The 
present study aims to investigate this variable in EFL reading skills. The current research is particularly interested in the following variables: gender, field of specialization, and language proficiency.

Surveys such as that conducted by Oxford and Nyikos (1989) have shown that Humanities and Science Education learners use resourceful and independent strategies more frequently than engineering, computer science, physical science, and business majors. Findings have revealed that Humanities/social science and education majors use more functional practice strategies than technical majors. Oxford and Nyikos (1989) maintain that this discrepancy is mainly related to students' awareness of these strategies and their willingness to develop a satisfactory communicative competence. They also point out that motivation has the most powerful effect on learning strategies.

\subsection{Reading strategies and Proficiency}

It is interesting to investigate whether students use effective reading strategies, especially when previous studies demonstrated that appropriate reading strategy use enhances reading comprehension (Olson \& Gee, 1991). Dreyer (1998) and Van Wyk (2001) noticed that some undergraduate students in tertiary institutions in South Africa often displayed low level of reading strategy knowledge and lacked the required strategies to achieve comprehension. Learners select inefficient strategies with little strategic intent (Wood, Motz, \& Willoughby, 1998) and most educators are unaware of students' cognitive processes while attempting to comprehend a text and what particular reading strategies they use.

A good number of empirical investigations have established a positive relationship between strategies and reading comprehension. Previous investigation also discovered that the use of appropriate strategies could enhance reading comprehension (Olson \& Gee, 1991). Brookbank, Grover, Kullerg, and Strawser (1999) have found that the use of various reading strategies improved students' reading comprehension.

Reading involves a variety of factors which may have an impact on learners' target language reading ability. Some of these factors are: learners' lack of target language proficiency and vocabulary (Kasper, 1993); unfamiliarity with the content and/ or formal schemata of the text to be read (Carrell \& Floyd, 1987, p. 2083), inefficient reading strategies (Carrell, 1989). Paris and Jacobs (1984) state "skilled readers often engage in deliberate activities that require planful thinking, flexible strategies and periodic self-monitoring...novice readers often seem oblivious to these strategies and the need to use them."

A number of studies have demonstrated that reading difficulties are closely linked to readers' level of proficiency in the target language and most of the studies mentioned previously have investigated the interaction between "proficiency level" and "strategy use". Usó-Juan (2006) insists that key variables such as first language (L1) reading or social and psychological variables (such as motivation, self confidence) and purpose for reading impact the reading act. Existing research has shown that, based on the specific needs of their research projects, professional readers make choices as to what to read. This means that when readers encounter difficulties in comprehending a text they use strategies to overcome comprehension difficulties. In recent years, many researchers have tried to investigate what proficient, skilled readers typically do while reading in both L1 and L2. Scholars have identified the types of strategies they use, how they use them, and under what conditions (Block, 2000; Jiménez, Garcia, \& Pearson, 1996; Pressley, Beard-El -Dinary \& Brown, 1992; Song, 1998).

The few studies that have investigated strategies in L1 and L2 contexts show that successful reading strategy use is dependent on metacognitive awareness of strategies, such as planning and consciously executing appropriate action, to achieve a particular goal (Carrell et al., 1989; Jiménez et al., 1996; Auerbach \& Paxton, 1997; Tercanlióglu, 2004).

All scholars who established a significant relationship between proficiency and awareness of reading strategies assert that it is important for all native and non-native readers to be aware of the necessary strategies proficient reading requires. Teachers can play an important role in increasing students' awareness of such strategies by helping them become active readers. Assisting less successful students, who are often unaware of their own cognitive process in acquiring and using successful reading strategies, seems to be a necessary step to enhance proficiency (Sheorey \& Mokhtari, 2001; Mokhtari \& Reichard, 2004).

Yet, investigation has demonstrated that strategy awareness and effective proficiency level cannot be completed without strategy training.

\section{Methodology}

\subsection{Population}

Echoing Mokhtari and Sheorey (2002) this study aimed to investigate the choice of reading strategies by Tunisian University students. The fieldworker aimed to identify an eventual correlation between SPECIALTY, GENDER, PROFICIENCY and Reading strategy use.

The participants were a group of 147 Tunisian University students majoring in four different disciplines (Soft Sciences: English and French, Hard Sciences: Medicine and Engineering). They had been exposed to English for 2 years at the University Level, with a minimum of two hours per week, except for English majors, whose all lectures are in English. Though gender is a variable to be investigated in this study, it was not possible to get the same number of males and females in any institute (Males: 31, Females: 116).

\subsection{Instruments}

Reading strategies have been investigated through several procedures such as observations (videotaping classrooms sessions and observations of tutorial sessions) or student self-report diaries (students write what they do to learn a language) (Khaldieh, 2000; Majid, Azman \& Jelas, 2010). Yet, these methods have been criticized because of the bias attitude that 
participants may adopt, and affect the reliability of the results. Dörnyei (2007) refers to the "Hawthorne effect" as the reactivity of the participants which might be altered when the latter know they are being observed. Participants may perform differently once they know they are studied. Thus, it may affect the validity of the results.

The strategies that were investigated had been inspired by the Metacognitive Awareness of Reading Strategies Inventory (MARSI) developed by Mokhtari (1998-2000). MARSI inspired the development of the Survey of Reading Strategies (SORS) as a new instrument considered to be more appropriate to measure non-native speakers' strategies. Survey of Reading Strategies (SORS) was designed by Mokhtari and Sheorey (2002, p. 2) as "a simple, yet effective tool for enabling students to develop a better awareness of their reading strategies, for helping teachers assess such awareness, and for assisting students in becoming constructively responsive readers." SORS aims at determining and evaluating learners' reading strategies, "mental plans, techniques and action" adopted once they read academic texts. Mokhtari and Sheorey (2002) argue that raising students' metacognitive awareness facilitates the development and progress of reading comprehension skills.

The SORS lists 30 reading strategies categorized into 3: Global Reading Strategies, Problem Solving Strategies and Support Strategies.Each item is on a Likert scale, and informants are required to identify their frequency use of each strategy, from 1 ("I never or almost never do this") to 5 ("I always or almost always do this").

In the current survey the Cronbach reliability test indicated that the alpha coefficient for SORS is .89, which suggests that the 30 items of the questionnaire has relatively high internal consistency. An adapted version of the SORS was given to the participants. The 30 strategies were reordered in a way different from its original version (Appendix A). The fieldworker classified the strategies according to the logical reading process and the stages readers go through while reading a text: Before reading, while reading and after reading. Since the objective of this instrument is to raise students' awareness of strategies, it seemed reasonable to classify the strategies according to the order the latter may be used in the reading process.

Before answering the SORS, participants had to read a text and answer comprehension questions. The objective of this task was to assess informants' awareness of the different strategies they use in the receptive skill. Then, the researcher transferred the scores obtained for each strategy to the scoring sheet (Appendix B) which accompanies the instrument. After individual scores were recorded, they were added up in each column to obtain a total score for the entire instrument (Overall Strategies) as well as for each strategy subscale (GLOB, PROB and SUP). The score average was interpreted using the high (mean of 3.5 or higher), moderate(mean of 2.5 to 3.4), and low usage(mean of 2.4 or lower) designations included on the scoring sheet.

The overall score average indicates how often students believe they use the strategies when reading academic materials. Mokhtari and Sheorey (2002) explain that the average, for each subscale in the inventory, shows the mean frequency with which students use a given category of strategies when reading academic material. The results obtained will help in this study to a) identify the frequency of the different strategies, b) determine relationships between proficiency and strategies use and c) analyse if students majoring in different specialties use particular types of strategies. After gathering data the researcher recorded all the results on an Excel table, to facilitate SPSS analyses. She used the IBM SPSS Software version 20.0 to undertake the analysis.

\section{Analysis}

\subsection{Reading Strategies across four Disciplines}

A precise analysis helped to determine if participants majoring in different specialisms prefer some specific reading strategies to others. A Spearman's rank-order correlation was run to analyze the relationship between Specialty, overall reading strategies, and the average of the three sub-strategies: GLOB, PROB and SUP.

Table 1. Correlation Matrix between Specialty and Reading strategies

\begin{tabular}{|c|c|c|c|c|c|c|c|}
\hline \multicolumn{8}{|c|}{ Correlations } \\
\hline & & & $\begin{array}{c}\text { Speciality_co } \\
\text { de }\end{array}$ & OLOB_ReaAN & PROB_ReaAv & SUP_REaAV & overall_Rea \\
\hline \multirow[t]{15}{*}{ Spearman's mo } & \multirow[t]{3}{*}{ Specialty_code } & Correlaton Coeficient & 1,000 &,$- 255^{\prime \prime}$ & $-.181^{\prime \prime}$ &,$- 583^{m}$ & -426 \\
\hline & & Sig. (2-tailed) & &, 002 & .028 & .000 &, 000 \\
\hline & & $\mathrm{N}$ & 147 & 147 & 147 & 147 & 147 \\
\hline & \multirow[t]{3}{*}{ GLOB_Realw } & Correlason Coeficient & $=255^{m}$ & 1,000 & $439^{\prime \prime}$ & $501^{-1}$ & $852^{\circ}$ \\
\hline & & Sig. (2-tailed) & .002 & . & .000 & .000 & .000 \\
\hline & & $\mathrm{N}$ & 147 & 147 & 147 & 147 & 147 \\
\hline & \multirow[t]{3}{*}{ PROB_ReaAY } & Correlason Coeficiant & $-181^{\prime}$ & $.439 "$ & 1,000 & $.347^{\prime \prime}$ & $657^{\prime \prime}$ \\
\hline & & Sig. (2-tailed) & .028 &, 000 & & 000 &, 000 \\
\hline & & $\mathrm{N}$ & 147 & 147 & 147 & 147 & 147 \\
\hline & \multirow[t]{3}{*}{ SUP_REaAV } & Correlanon Coeficient &,$- 583^{\prime \prime}$ & $.501^{\prime \prime}$ & $.347^{\prime \prime}$ & 1,000 & $.757^{\prime \prime}$ \\
\hline & & Sig. (2-tailed) & .000 &, 000 & .000 & &, 000 \\
\hline & & $\mathrm{N}$ & 147 & 147 & 147 & 147 & 147 \\
\hline & \multirow[t]{3}{*}{ Overall_Rea } & Correlafon Coeficient &,$- 426^{-1}$ & $852^{\prime \prime}$ & $.667^{\prime \prime}$ & $.757^{\circ}$ & 1,000 \\
\hline & & Sig. (2-tailed) & .000 & .000 & .000 & $\infty$ & \\
\hline & & $\mathrm{N}$ & 147 & 147 & 147 & 147 & 147 \\
\hline
\end{tabular}


Table 1 shows a negative correlation between SPECIALTY_Code and GLOB_ReaAv (Average of Global Reading strategies), PROB_ReaAV (Average of problem solving Reading strategies), SUP_ReaAv (Average of Support Reading strategies), and overall_Rea (Average of Overall reading strategies) which are the dependent variables (Correlation coefficients range from -0.181 to -0.583). As explained by Riazi (2016, p. 64) in The Routledge Encyclopedia of Research Methods in Applied Linguistics, negative correlation means the 2 variables are in a reverse relationship with each other (when one goes up, the other goes down and vice versa). SPECIALTY correlates significantly but negatively with OVERALL READING STRATEGIES, which is statistically significant $\left(r_{s}(147)=-.426, p=.000\right)$ with an $\mathrm{R}^{2}=.15$ or $15 \%$, which can be considered, according to Cohen's (1992) classification, as a medium effect $\left(\mathrm{R}^{2}=.01\right.$ small effect, $\mathrm{R}^{2}=.09$ medium effect, $\mathrm{R}^{2}=.25$ large effect). $\mathrm{R}^{2}$ or the correlation of strength effect has been obtained through Measures of Association. Larson-Hall (2010, p. 161) defines $\mathrm{R}^{2}$ or the correlation power effect “...as a measure of how much of the variance in one variable is accounted for by the other variable". Loewen and Plonsky (2016, pp. 56-58), explain that the effect size is a "descriptive statistic that expresses the magnitude of strength of a relationship....and $\mathrm{R}^{2}$ expresses shared variance". In the current case the correlation between SPECIALTY and OVERALL AVERAGE OF READING STRATEGIES indicate a medium strength effect $\left(\mathrm{R}^{2}=15 \%\right)$ which indicates a moderate relationship between the two variables.

4.2. Global Reading strategies (GLOB Reading Strategies)

SPECIALTY and GLOB_ReaAv $(r=-0.255, p=.002)$ correlate as well negatively with a small effect $\left(\mathrm{R}^{2}=.06\right)$. Similarly, SPECIALTY and PROB_ReaAv reading strategies correlate negatively $\left(r=-0.181, p=.028, \mathrm{R}^{2}=.02\right)$. Correspondingly, there is a strong and negative correlation between SPECIALTY and SUP_ReaAV reading strategies $(\mathrm{r}=-0.583, p=.000)$ but with a large part of the variance with an $\mathrm{R}^{2}$ of $31 \%$. The negative correlation illustrates a reverse relationship between SPECIALTY and READING STRATEGIES, in other words, the more we rise in the list of specialties, from Soft sciences to Hard Sciences (English, French, Medicine and Engineering), the frequency of reading strategies decreases.

These results indicate that soft science students tend to use more reading strategies than hard science students. English and French students are ranked first in the data, followed respectively by Medicine and Engineering students. This suggests that the less students are exposed to English language the less reading strategies they use. English students attend all their courses in English, while French, Medicine, and Engineering students have an average of 2 hours of English per week. It is possible then, that the amount of English instruction affects students' awareness and use of learning strategies.

In order to find out how students majoring in different specialties differ in their use of the different reading strategies, an ANOVA (Analysis of Variances) with an F-test was run to assess the statistical significance of the resulting difference among the four groups (English, French, Medicine and Engineering majors). Results provide descriptive statistics, including the mean and standard deviation for each separate group (English, French, Medicine and Engineering), as well as when all groups are combined (Total). The first result of the ANOVA test provides us with a descriptive of data: Number (N), Mean (M) and Standard Deviation (SD). The Two main measures or descriptive statistics commonly reported are the mean and standard deviation. These two measures provide information about the distribution of the sample of the study (Riazi, 2016).

The calculation of means of the different strategies used per groups permitted the identification of the different reading strategies rate of recurrence, in addition to participants' reading proficiency level. Oxford (1990, pp. 297-300) explains that overall Reading strategies indicate how often students use reading strategies when reading academic materials. According to the key to averages she designed (3.5 or higher= High, 2.5-3.4= Medium, 2.4 or lower= Low), the findings in this study indicate that Tunisian students are Medium users (overall_Rea, $\mathrm{M}=3.32, \mathrm{SD}=.48$ ) of reading strategies.

The total AVERAGE of Reading strategies (overall_Rea) is 3.32 (SD=.4825), with English students ranked first with a mean of $3.64(\mathrm{SD}=.30)$. They can be considered as high users of strategies. They are followed by French majors $(\mathrm{M}=3.31$, $\mathrm{SD}=.56)$, Medicine majors $(\mathrm{M}=3.26, \mathrm{SD}=.41)$ and finally Engineering majors $(\mathrm{M}=3.09, \mathrm{SD}=.45)$.

It seems that Soft science students are slightly more aware of strategies than Hard science students even if it does not impact directly on proficiency as medicine majors proved to have a higher proficiency level than the other students. Additionally we can notice that the standard deviation (SD) within the groups is not at the level of READING STRATEGY USE (overall-Rea, GLOB-ReaAV, PROB_ReaAV, SUP_ReaAV). The standard deviation is a tests used to identify the degree of variability within the sample (Riazi, 2016). Table 1 indicates that there is not a high within-group dispersion since SD is below 1 and ranges between .30 and .73. This indicates that the four groups are homogeneous.

Though Tunisian EFL students appear to be medium users, it would be interesting to find if the field of specialization impacts the choice and frequency of strategies. Since Humanities students seem to be more frequent users, it would be interesting to identify a possible relationship between each specific specialty and the different strategies. The objective of this analysis is to find out if there is a difference at the level of results that may lead to clear distinction between the different specialisms and the utilization of the diverse reading strategies.

Results indicate a difference in Prof_Rea (proficiency level) among the different specialties. English (M=9.03, SD=1.90), Medicine Majors ( $M=9.47, \mathrm{SD}=1.46)$, and Engineering Majors $(\mathrm{M}=8.72, \mathrm{SD}=2.12)$ revealed a higher proficiency level and little variance within the groups in comparison to the French Majors. French students displayed a low proficiency level (M= 4.12) with a high degree of variance within the group $(\mathrm{SD}=3.16)$.

Despite the difference in proficiency level among the different specialties, and the little discrepancy in the frequency of reading strategy use, there is nevertheless a difference in the types of strategies used. This last point was verified with Spearman rank order correlation and confirmed by the ANOVA analysis which validated significant difference between groups as illustrated in Table 2 below. The one-way ANOVA test (Table 2) was conducted to compare the effect of 
SPECIALTY on OVERALL READING STRATEGIES and the different SUB-READING STRATEGIES: GLOB, PROB, SUP. Table 2 shows the output of the analysis of variance and whether there is a statistically significant difference between the group means.

Table 2. Summary of results of ANOVA for reading strategies in the different specialties

\begin{tabular}{|ll|l|l|l|l|l|}
\hline & & Sum of Squares & df & Mean Square & F & Sig. \\
\hline \multirow{2}{*}{ GLOB_ReaAv } & Between Groups & 3.309 & 3 & 1.103 & 3.256 & .024 \\
& Within Groups & 48.440 & 143 & .339 & & \\
& Total & 51.749 & 146 & & & \\
& Between Groups & 6.689 & 3 & 2.230 & 6.654 & .000 \\
PROB_ReaAv & Within Groups & 47.915 & 143 & .335 & & \\
& Total & 54.604 & 146 & & & \\
SUP_ReaAV & Between Groups & 18.379 & 3 & 6.126 & 22.919 & .000 \\
& Within Groups & 38.226 & 143 & .267 & & \\
& Total & 56.606 & 146 & & & \\
& Between Groups & 5.893 & 3 & 1.964 & 9.997 & \\
overall_Rea & Within Groups & 28.097 & 143 & .196 & & \\
& Total & 33.990 & 146 & & & \\
\hline
\end{tabular}

ANOVA showed that the effect of SPECIALTY on overall_Rea was significant, $\mathrm{F}(3,143)=9.99, p=0.000$ and thus there is a statistical significant difference between groups.

Similarly ANOVA indicates a significant difference between groups in the sub-categories of Reading strategies: GLOB_ReaAv, PROB_ReaAv and SUP_ReaAv. The main effect of SPECIALTY in GLOB_ReaAv is F $(3,143)=3.25$, $p=.024$. Nevertheless, it is less statistically significant than the effect of specialty groups in their use of PROB and SUP reading strategies as in PROB_ReaAv reading strategies it is $\mathrm{F}(3,143)=6.65, p=.000$ and in SUP_ReaAV F(3,143)= 22.91, $p=.000$. The respective average in the four categories of Reading strategies is below 0.05 , and consequently is highly significant.

The Tukey Post-Hoc test (Table 3) indicates a significant difference in global reading strategy use between English students and Engineering students, $(p=0.014)$.

Table 3.Output from the one-way ANOVA Post-Hocs: GLOB Reading strategies among four specialties

\begin{tabular}{|c|c|c|c|c|c|}
\hline Dependent Variable & (I) Speciality_code & (J) Speciality_code & $\begin{array}{l}\text { Mean } \\
\text { Difference (I-J) }\end{array}$ & Std. Error & Sig. \\
\hline \multirow{12}{*}{ GLOB_ReaAv } & \multirow{3}{*}{ English } & French & .22159 & .14027 & .698 \\
\hline & & Medecine & .25346 & .13537 & .379 \\
\hline & & Engineering & $.41583^{*}$ & .13371 & .014 \\
\hline & \multirow{3}{*}{ French } & English & -.22159 & .14027 & .698 \\
\hline & & Medecine & .03187 & .13849 & 1.000 \\
\hline & & Engineering & .19424 & .13687 & .948 \\
\hline & \multirow{3}{*}{ Medecine } & English & -.25346 & .13537 & .379 \\
\hline & & French & -.03187 & .13849 & 1.000 \\
\hline & & Engineering & .16237 & .13184 & 1.000 \\
\hline & \multirow{3}{*}{ Engineering } & English & $-.41583^{*}$ & .13371 & .014 \\
\hline & & French & -.19424 & .13687 & .948 \\
\hline & & Medecine & -.16237 & .13184 & 1.000 \\
\hline
\end{tabular}

ANOVA and Post-Hoc tests were run to determine in detail where majors of different specialties varied in their use of the 13 GLOB Reading strategies. The two tests revealed a significant discrepancy in five individual GLOB strategies, and more specifically between English and Hard Science majors (Medicine and Engineering). Students differ in strategy 3, "I think about what I know to help me understand what I read", strategy 6 "I think about whether the content of the text fits my reading purpose", strategy 19 "I try to picture or visualize information to help myself remember what I read", strategy 23 "I check my understanding when I come across new information" and strategy 28 "When I read, I guess the meaning of unknown words or phrases". In these five strategies, the Tukey Post- Hoc test and descriptive tables reveal that English students are higher users of these strategies than Medicine, Engineering and French majors, who are medium users. These findings might be related to the different language learning instruction they get at their respective institutions. While English 
instructors at Arts faculties accentuate rhetorical instruction and may stress these strategies, perhaps implicitly, English teachers at scientific institutions seem to emphasize ESP vocabulary instruction.

4.3. Problem Solving Reading Strategies (PROB Reading Strategies)

Table 1 indicates that SPECIALTY correlates significantly but negatively with Prob_ReaAV (Problem solving reading strategies) which is statistically significant $(r=-0.181, p=.028)$. ANOVA test (Table 2$)$ demonstrates that the effect of SPECIALTY on Prob_ReaAv is not only significant but also reveals an interesting discrepancy between groups, F $(3,143)=$ $6,65, p=0.000$.

English majors are also ranked first users of PROB reading strategies $(\mathrm{M}=4.10, \mathrm{SD}=.39)$ followed by Medicine $(\mathrm{M}=3.82$, $\mathrm{SD}=.56)$, Engineering $(\mathrm{M}=3.72, \mathrm{SD}=.57)$ and French majors $(\mathrm{M}=3.49, \mathrm{SD}=.73)$. We notice that Medicine, Engineering and French students are more comfortable with PROB reading strategies than with GLOB strategies as they are medium users of the latter category, while they are high users of the former.

Table 4. Output from the one-way ANOVA Post-Hocs: PROB_ Reading strategies among four specialties

\begin{tabular}{|c|c|c|c|c|c|}
\hline Dependent Variable & (I) Speciality_code & (J) Speciality_code & $\begin{array}{l}\text { Mean } \\
\text { Difference (I-J) }\end{array}$ & Std. Error & Sig. \\
\hline \multirow{12}{*}{ PROB_ReaAv } & \multirow{3}{*}{ English } & French & $.61033^{*}$ & .13950 & .000 \\
\hline & & Medecine & .28060 & .13463 & .234 \\
\hline & & Engineering & $.38464^{*}$ & .13298 & .027 \\
\hline & \multirow{3}{*}{ French } & English & $-.61033^{*}$ & .13950 & .000 \\
\hline & & Medecine & -.32973 & .13774 & .108 \\
\hline & & Engineering & -.22569 & .13613 & .597 \\
\hline & \multirow{3}{*}{ Medecine } & English & -.28060 & .13463 & .234 \\
\hline & & French & .32973 & .13774 & .108 \\
\hline & & Engineering & .10404 & .13113 & 1.000 \\
\hline & \multirow{3}{*}{ Engineering } & English & $-.38464^{*}$ & .13298 & .027 \\
\hline & & French & .22569 & .13613 & .597 \\
\hline & & Medecine & -.10404 & .13113 & 1.000 \\
\hline
\end{tabular}

The Tukey Post-Hoc Test (Table 4) indicates a statistical difference between English students and French majors ( $p=.000)$ and between the English group and Engineering majors $(p=.027)$ in the average of Prob_ReaAv. But there is no statistical difference between Medicine and Language Majors (English students: $p=.234$; French students: $p=.108$ ). Similarly, Medicine and Engineering majors seem to have an equal frequency rate use of PROB reading strategies as $p=1.000$,

Similarly to GLOB strategies, findings reveal divergent frequency levels of individual PROB reading strategies among participants in the four groups. Results show that there is a strong statistical difference between groups in six individual PROB_Rea strategies as the significance level is $p<0.5$.

There is no statistical difference between participants in their use of item 11 "I stop from time to time and think about what I am reading" and item 25 "I try to picture or visualize information to remember what I read" as the significance level respectively indicates $p=.294$ and $p=.971$ which is superior to .05 .

The descriptive statistics for the PROB_ReaAv strategies show that Medicine students have the highest mean in item 5 "I adjust my reading speed according to what I am reading" $(X=4.08, \mathrm{SD}=.95)$ and item 13 "I try to get back on track when $\mathrm{I}$ lose concentration" $(\mathrm{X}=4.47, \mathrm{SD}=.79)$. English students rank first in item 4 "I read slowly and carefully to make sure I understand what I am reading" $(\mathrm{X}=4.47, \mathrm{SD}=.84)$, item 9 " When text becomes difficult; I pay closer attention to what $\mathrm{I}$ am reading" $(\mathrm{X}=4.53, \mathrm{SD}=.60)$, item 16 "When I read, I guess the meaning of unknown words or phrases" $(\mathrm{X}=4.28, \mathrm{SD}=.91)$, $25(\mathrm{X}=3.33, \mathrm{SD}=1.30)$ and item 30 "When text becomes difficult, I re-read it to increase my understanding" (X=4.69, $\mathrm{SD}=.57)$.

However, there is no regularity in students' use of individual PROB reading strategies or any distinct preference of any type of strategies as in most cases Standard deviation level is $>1$ This means that there is no perfect regularity as for the mean and that the data points tend to be spread out over the wide range of values, which indicates an absence of homogeneity among the students in their use of problem solving strategies.

4.4. Support Reading Strategies (SUP Reading strategies)

Similarly to the previous sub-categories of strategies, Spearman rank order (Table 1) demonstrates that the effect of SPECIALTY on SUPPORT READING STRATEGIES is also noteworthy. It reveals a negative correlation between SPECIALTY and SUP Rea_AV ( $\mathrm{r}=-0.583, p=.000)$. ANOVA test (Table 2) confirms an interesting difference between groups $(\mathrm{F}(3,143)=22.91, p=0.000)$. As the significance value in Sup Rea_Av is 0.000 (i.e., $p=.000)$, consequently, there is a statistical significant difference in the use of Support reading strategies between the different groups of students $(p=.000<.05)$, except in between Soft Science groups (French vs English, $p=.794)$ and Hard science groups (Medicine vs Engineering, $p=.480$ ) 
In contrast with GLOB and PROB reading strategies, students are Medium users of these SUP strategies as average (X) varies from 3.39 to 2.52 (Table11). Like in the previous categories, English majors are ranked first $(\mathrm{X}=3.39, \mathrm{SD}=.42)$, followed respectively by French $(X=3.21, S D=.63)$, Medicine $(X=2.73, S D=.51)$ and Engineering $(X=2.52, S D=.49)$ students. Nevertheless, despite that order we can observe an irregularity and absence of consistency in the frequency use of some SUP reading strategies. The second multi-variance analysis of SUP reading strategies identifies precisely which individual strategies majors prefer among others.

\section{Discussion}

\subsection{Specialty and Reading Strategies}

The current research aimed to identify any relationship between SPECIALTY and Reading STRATEGIES. Humanities students revealed to be more conscious of strategies than Hard science students (Medicine and Engineering), hence the higher frequency rate of strategy use. English and, in some cases, French students are ranked first followed respectively by Medicine students and Engineering students. These findings are, to some extent, in line with previous studies which demonstrated that English students are higher users of learning strategies in comparison to Science students (Mockizuki, 1999; Peacock, 2001, Peacock and Ho, 2003). Yet, the present study did not identify a connection between field of specialization and types of strategies. It indicated no distinct association between any specialty and any sub-strategy group. This last observation is suggestive that EFL learners, though majoring in different specialisms, do not differ much from each other when it comes to English language learning. However, findings demonstrated that students, regardless of their specialty, are more comfortable with Cognitive strategies (PROB), followed respectively by metacognitive strategies (GLOB) and support strategies (SUP). In the Tunisian context, the main reason behind students'choice of strategy and rate of reccurence might be due to the training and time of exposure to English languaage. French, Medicine and Engineering students attend English classes at the average of two hours per week, while English majors attend all their courses in English. Yet, this discrepancy of time exposure is not reflected in the reading performance of English majors. Despite their awareness of reading strategies, they do not seem to make efficient use of them to enhance their reading proficiency level.

\subsection{Proficiency and Reading Strategies}

Results demonstrate that frequency of strategies is not necessarily related to proficiency level. Participants show that in spite of low frequency of strategy use they may perform well in reading. Though Science students reveal a low rate of strategy use, this does not seem to impact on proficiency level. Medicine students performed better than the other majors in Reading $(X=9.47, S D=1.46)$, while French majors have the lowest reading performance $(X=4.12, S D=3.16)$. Nevertheless, this discrepancy may be related to their secondary level school achievements.

Song (1998) and Khaldieh (2000) report that some learners may be aware of strategies but do not exploit them actively, whereas skilled students may use them effectively. It is then, necessary to distinguish between frequency and efficiency. Saumell, Hughes and Lopate validate (1999) that lack of proficiency in reading is related to a selection of ineffective use of strategies. Usò-Juan (2006) claims that different factors contribute to effective reading performance such as discipline related knowledge, first language reading (L1), and even motivation and self confidence.

Results of the different correlation tests demonstrate that there is no relationship between SPECIALTY and READING PROFICIENCY. Yet, this fact suggests that students' behaviour towards EFL, social and psychological variables such as motivation, and the desire to reach perfection, may be key factors behind learners' proficiency level. In the Tunisian context, it is possible that motivation, shortage of time or lack of inclination to English language are major causes behind learners' proficiency level. Students' attitude might be explained by the high rate of absenteeism.

The findings of this investigation complement those of earlier studies. Peacock (2001) observed that tertiary level students used mainly cognitive and compensation strategies, while nine metacognitive strategies are associated with levels of proficiency. Peacock and Ho (2003) noted that higher levels of proficiency are associated with 27 individual strategies among 50, which are mainly cognitive and metacognitive. The findings in the current study indicate that proficient students seem to favor PROB strategies in Reading. Yet, previous investigations underline that the two types of strategies work in tandem and complete each other to achieve proficiency (Cook, 2008; Díaz Larenas et al, 2017). The successful learner is the one who succeeds in the effective transfer from metacognitive to cognitive strategies, according to the situation (Vaidya, 1999).

\subsection{Gender and Reading Strategies}

Many studies (Oxford, Nyikos \& Ehrman, 1988; Oxford \& Ehrman's, 1995; Oxford, 2003) investigated GENDER as a variable that could correlate with learning strategies. These aimed to identify which types of strategies are related to gender. Most investigations concluded that females are more frequent users of strategies than males, and differed as well in their selection of strategies.

The findings of the current research are broadly similar to previous studies. The results of the correlation test revealed a negative correlation between GENDER and OVERALL READING STRATEGIES. $(\mathrm{r}=-.171, \mathrm{p}=0.038<0$. 05). This result supports the idea that females use more reading strategies $(X=3.35, \mathrm{SD}=.49)$ than males $(\mathrm{X}=3.17, \mathrm{SD}=.42)$, and in the different sub categories, with a preference for SUPPORT READING STRATEGIES ( $\mathrm{r}=-.277$, $\mathrm{p}=.001)$. Tunisian Female students unveiled a preference for eight individual strategies in reading that are strategy 3 (GLOB) 'I have a purpose in mind when I read', strategy 4 (PROB) "I read slowly and carefully to make sure I understand what I read", strategy 10 (SUP) 
"When text becomes difficult, I read aloud to help me understand what I read", strategy 17 (SUP) "When reading, I translate from English into my native language, strategy 18 (SUP) "I take notes while reading to help me understand what I read", strategy 21 (SUP) "I paraphrase (restate ideas in my own words) to better understand what I read", strategy 22 (SUP) "I underline or circle information in the text to help me remember it", and strategy 24 (SUP) "I use reference materials (eg. dictionary) to help me understand what I read".

Though Females use more strategies than males, who do not seem to favour any type, this fact does not seem to improve their proficiency level. Their strategy use is not reflected in their performances in either skill. The findings of the study indicated that there is no correlation between GENDER and PROFICIENCY either in Reading (rs $(147)=.146, p=.078)$. This result can only stress the different between adopting a strategy and using it efficiently.

\section{Conclusion and Recommandations}

Echoing previous studies, this paper attempted to investigate reading stategies in relation to Specialism, Gender, and Proficiency by using Mokhtari and Sheorey's Survey (SORS, 2002). Results are in line with previous research, only to some degree. Though Humanities students unveiled to be more aware of reading strategies than Hard Science students, there is little if no difference regarding the types of strategies.

The study concentrated as well on identifying strategies related to proficiency. Results showed a positive and strong correlation between PROFICIENCY and the Problem-solving READING STRATEGIES (Cognitive reading strategies). Findings revealed no statistical relationship between PROFICIENCY and Support (SUP) STRATEGIES, which implies that university level students are not interested in them or do not consider them important.

Due to the similar constructive and meaning-making nature of Reading, the current investigation of the strategies among Tunisian tertiary level students hopes to have pedagogical implications. These will permit instructors to tailor their instructions and enhance their pedagogy by focusing on strategies that permit learners to improve their proficiency level.

Results of the present study have confirmed that university majors are not aware of the effectiveness of reading strategies. Though language majors display a more frequent use of strategies, they do not seem to use them efficiently, hence their limited proficiency level of reading performances. There is, therefore, a definite need for explicit instruction. Strategies should be taught through direct explanation and extensive feedback. Explicit training in reading strategies could be of great value in helping students resort to their discipline-related knowledge, compensate for a low level of linguistic knowledge, and to achieve comprehension.

Instructors can help their students evaluate and reflect by asking them for instance, how they read and how they comprehend the text.

Another important practical implication is related to teachers' need to highlight the strategies that strongly correlate with proficiency level (in the current study the Global and Problem solving strategies/ Metacognitive and Cognitive strategies). This may have pedagogical implication for effective teaching and learning and may help learners enhance the reading performances. Findings revealed that Tunisian tertiary level students tend to use cognitive strategies (Problem-solving) more frequently than metacognitive (Global) strategies.

The objective of the study was to determine whether students differed in their learning processes. Yet, as no differences distinguish different majors, it is advisable for their instructors to tailor the course to their needs and raise students' awareness on reading strategies.

Gender is the third independent variable investigated in this study. Findings are consistent with other research. A detailed analysis demonstrated that female students appear to be more frequent users of Reading strategies than male students. Female participants showed a clear preference for support strategies in the reading skill. Still, it is possible that these results are due to the number of Female participants that exceeds the number of males, which might have impacted the nature of the results. However, it is necessary to note that the population that participated in the survey is reflective of the Tunisian academic population. In spite of female's more frequent use of strategies, there is no evident relationship between Gender and Proficiency level. Female students do not make efficient use of these strategies. Yet, the smaller number of university male students does not allow for a very confident conclusion.

\section{References}

Auerbach, E., \& Paxton, D. (1997). "It's not the English thing": bringing reading research into the ESL classroom. TESOL Quarterly, 31(2), 237-261.

Block, E. (1986). The comprehension strategies of second language readers. Tesol Quarterly, 20(3), 463-494.

Block, D. (2000). Problematizing interview data: Voices in the mind's machine? Tesol Quarterly, 34(4), 757-763.

Brookbank, D., Grover, S., Kullberg, K., \& Strawser, C. (1999). Improving Student Achievement through Organization of Student Learning.

Brown, H. D. (2007). Principles of language learning and teaching. ( $5^{\text {th }}$ ed.) White Plains, N.Y.: Pearson Education.

Carrell, P.L. (1989).Metacognitive awareness and second language reading. Modern Language Journal, 73 (2), $121-133$.

Carrell, P. L. (1998). Can reading strategies be successfully taught?. Australian review of applied Linguistics, 21(1), 1-20. 
Carrell, P.L. \& Floyd, P. (1987).Effects on ESL reading of teaching cultural content schemata.Language Learning, 37(1), 89108.

Carrell, P.L., Pharis, B.G., \& Liberto, J.C. (1989).Metacognitive strategy training for ESL reading. TESOL Quarterly, 23(4), 647-678.

Cohen, J. (1992). A Power Primer. Psychological Bulletin, 122(1), 155-159.

Cook, V. (2008). Second language learning and language teaching. Hodder Education

Díaz Larenas, C., Ramos Leiva, L., \& Ortiz Navarrete, M. (2017). Rhetorical, Metacognitive, and Cognitive Strategies in Teacher Candidates' Essay Writing. Profile Issues in TeachersProfessional Development, 19(2), 87-100.

Dörnyei,Z. (2007). Research methods in applied linguistics: Quantitative, qualitative and mixed methodologies. Oxford University Press.

Dreyer, C. (1998). Improving students' reading comprehension by means of strategy instruction. Journal for Language Teaching, 31 (1), 18-29.

Flavell, J. (1979). Metacognition and cognitive monitoring: a new era of cognitive- development inquiry. American Psychologist, 34(10), 906-911.

Grabe, W. (2014). Key issues in L2 reading development. In Proceedings of the 4th CELC Symposium for English Language Teachers-Selected Papers (pp. 8-18).

Janzen, J. (2002). Teaching strategic reading. Methodology in language teaching: An anthology of current practice, $287-294$.

Jiménez, R. T., García, G. E., \& Pearson, P. D. (1996). The reading strategies of bilingual Latina/o students who are successful English readers: Opportunities and obstacles. Reading Research Quarterly, 31(1), 90-112.

Kasper, L. F. (1993). The keyword method and foreign language vocabulary learning: A rationale for its use. Foreign Language Annals, 26 (2), 244-251.

Khaldieh, S.A. (2000). Learning Strategies and writing processes of proficient vs less- proficient learners of Arabic. Foreign Language Annals,33(5), 522-533.

Larson-Hall, J. (2010). A guide to doing statistics in second language research using SPSS. Routledge.

Lee, K. R., \& Oxford, R. (2008).Understanding EFL learners' strategy use and strategy awareness. Asian EFL Journal, 10(1), 7-32.

Levine, A., Ferenz, O., \& Reves, T. (2000). EFL academic reading and modern technology: How can we turn our students into independent critical readers. TESL-EJ, 4(4), 1-9.

Littlewood, W., \& Liu, N. F. (1996). Hong Kong students and their English. Macmillan Publishers (China) Limited.

Loewen, S. \& Plonsky, L. (2016).An A-Z of Applied Linguistics Research Methods. PALGRAVE.

Lynch, B. \& Hudson, T. (1991). EST Reading. In M. Celce-Muria (ed) Teaching English as a second or foreign language $\left(2^{\text {nd }}\right.$ ed $)$. pp 216-232. New York: Newsbury House.

Majid, F. A., Azman, N., \& Jelas, Z. M. (2010).The reading strategies of proficient and less proficient adult readers. Journal of Adult and Continuing Education, 16(1), 21-40.

Mochizuki, A. (1999). Language learning strategies used by Japanese university students. RELC Journal 30 (2), $101-113$.

Mokhtari, K. (2000). Metacognitive-Awareness-of-Reading-Strategies-Inventory (MARSI).Unpublished Doctoral Thesis. Oklahoma State University, Oklahoma, USA

Mokhtari, K., \& Reichard, C. (2004). Investigating the strategic reading processes of first and second language readers in two different cultural contexts. System, 32(3), 379-394.

Mokhtari, K., \& Sheorey, R. (2002).Measuring ESL students' awareness of reading strategies. Journal of Developmental Education, 25 (3), 2-11.

Olson, M. W., \& Gee, T. C. (1991). Content reading instruction in the primary grades: Perceptions and strategies. The Reading Teacher, 45(4), 298.

O’Malley, J. M. \& Chamot, A. U. (1990). Learning strategies in second language acquisition. Cambridge University Press.

Oxford, R. L. (1989). Use of language learning strategies: A synthesis of studies with implications for strategy training. System, 17(2), 235-247.

Oxford, R. L. (1990). Language learning strategies: What every teacher should know ; Boston: Heinle\& Heinle Publishers.

Oxford, R. L. (2003). Language learning styles and strategies: Concepts and relationships. International review of applied linguistics in language teaching, 41(4), 271-278.

Oxford, R. L. \& Ehrman, M. E. (1995). Adults' language learning strategies in an intensive foreign language program in the United States. System 23(3), 359-386.

Oxford, R. L., \& Nyikos, M. (1989).Variables affecting choice of language learning strategies by university students. The modern language journal, 73 (3), 291-300.

Oxford, R. L., Nyikos, M., \& Ehrman, M. E. (1988). Vive la difference? Reflections on sex differences in use of language learning strategies. Foreign Language Annals, 21(4), 321-328.

Paris, S., \& Jacobs, J. (1984).The benefits of informed instruction for children's reading awareness and comprehension skills. Child Development, 2083-2093.

Peacock, M. (2001). Language learning strategies and EAP proficiency: teacher views, student views, and test results. In J. Flowerdew and M. Peacock, Research Perspectives on English for Academic Purposes.(pp.268-85). Cambridge University Press. 
Peacock, M., \& Ho, B. (2003).Student Language learning strategies across eight disciplines.International Journal of Applied Linguistics, 13(2), 179-200.

Pressley, M., \& Afflerbach, P. (1995).Verbal protocols of reading: The nature of constructively responsive readings. Mawah, NJ: Lawrence Erlbaum.

Pressley, M., Beard-El-Dinary, P., \& Brown, R. (1992). Skilled and not so-skilled reading: good information processing and not-so-good information processing. In M. Pressley, K., Harris\& J. Guthrie (Eds.), Promoting Academic Competence and Literacy in Schools (pp. 91-127).San Diego, CA: Academic Press.

Pritchard, R. (1990). The effects of cultural schemata on reading processing strategies. Reading Research Quarterly, 273295.

Riazi, A. M. (2016). The Routledge Encyclopedia of research methods in Applied Linguistics. Routledge.

Saumell, L., Hughes, M. and Lopate, K. (1999). Underprepared college students' perceptions of reading: are their perceptions different from other students? Journal of College Reading and Learning,29(2),123-135. DOI: $10.1080 / 10790195.1999 .10850074$

Sheorey, R., \& Mokhtari, K. (2001). Differences in the metacognitive awareness of reading strategies among native and nonnative readers.System, 29 (4), 431- 449.

Song, M. (1998). Teaching reading strategies in an ongoing EFL university reading classroom.Asian Journal of English Language Teaching, 8 (1), 41-54.

Tercanlioglu, L. (2004). Postgraduate Students' Use of Reading Strategies in L1 and ESL Contexts: Links to Success. International Education Journal, 5 (4), 562-570.

Usó-Juan, E. (2006). The compensatory nature of discipline -related knowledge and English-Language proficiency in reading English for academic purposes.The Modern Language Journal, 90, (2), 210-227.

Vaidya, S. R. (1999). Metacognitive learning strategies for students with learning disabilities. Education, $120(1)$, $186-186$.

Van Wyk, A. L. (2001). The development and implementation of an English language and literature programme for lowproficiency tertiary learners (Doctoral dissertation, University of the Free State).

Wood, E., Motz, M., \& Willoughby, T. (1998).Examining students' retrospective memories of strategy development. Journal of educational psychology, 90(4), 698-704. 